\title{
Actividades de imagen en la expresión sexista de la violencia simbólica y la descortesía verbal
}

\section{Facework activities in the sexist expression of symbolic violence and impoliteness}

\author{
Gabriel Ignacio Verduzco Arguelles (iD) Eduardo Ruiz Pérez (ic) \\ Stella Maris Rodríguez Tapia \\ Universidad Autónoma de Coahuila, Coahuila, México. \\ gabrielverduzco@uadec.edu.mx \\ eduardoruizperez@uadec.edu.mx \\ stellardztapia@gmail.com
}

\section{G ACCESO ABIERTO / OPEN ACCESS}

Cita: Verduzco Arguelles, Gabriel I., Ruiz Pérez, Eduardo, Rodríguez Tapia, Stella Maris. Actividades de imagen en la expresión sexista de la violencia simbólica y la descortesía verbal. Textos en Proceso, 5.2, pp. 75-86. http://doi.org/10.17710/tep.2019.5.2 6verduzco

Editors: Ariel Cordisco, Instituto de Lingüística, Universidad de Buenos Aires, Argentina; Ma Eugenia Flores Treviño, Universidad Autónoma de Nuevo León, México

Recibido: 20/02/2020

Aceptado: 10/05/2020

Conflicto de intereses: Los autores han declarado que no poseen conflicto de intereses.

Copyright: @ G. I. Verduzco Arguelles. Esta obra está bajo licencia Creative Commons Reconocimiento 4.0

\section{Resumen}

Este trabajo forma parte del proyecto conjunto entre México y Argentina de estudios sobre sexismo y son los resultados de la réplica del estudio "Actividades comunicativas en la expresión sexista de la la descortesía verbal", presentado por el Dr. Ariel Cordisco en el XII Congreso ALED en Santiago de Chile en octubre de 2017. Para replicar el estudio se empleó el cuestionario utilizado para el caso argentino adaptado al contexto sociocultural del noreste de México. El trabajo explora, a partir de las respuestas que escriben los sujetos en el cuestionario, cómo se construyen las posiciones enunciativas sexistas exclusivas de hombres y mujeres, así como los recursos comunicativos descorteses que se activan y el ámbito en función - público o privado- en el cual aparecen. Como principal hallazgo, se puede mencionar que los recursos comunicativos descorteses se orientan a la sexualidad, a la capacidad intelectual y a las habilidades, de hombres y de mujeres, tanto en lo público y en lo privado.

Palabras clave: discurso social; sexismo; violencia simbólica; descortesía.

\begin{abstract}
This work is part of the joint project between Mexico and Argentina of studies on sexism and are the results of the replication of the study "Communicative activities in the sexist expression of verbal impoliteness", presented by Dr. Ariel Cordisco at the XII ALED Congress in Santiago de Chile in October 2017. To replicate the study, was used the argentine case questionnaire for the adapted to the sociocultural context of northeast Mexico. The work explores, from the answers that the subjects write in the questionnaire, how are constructed the exclusive sexist enunciative positions of men and women, as well as impolite communicative resources that are
\end{abstract}


activated, and the scope in function - public or private- in which they appear. As main finding, it can be mentioned that impolite communicative resources are oriented to sexuality, to intellectual capacity and abilities, of men and women, both publicly and privately.

Keywords: social discourse; sexism; symbolic violence; impoliteness.

\section{Introducción}

Durante el desarrollo del XII Congreso ALED en Santiago de Chile (2017), investigadores de la Universidad de Río Cuarto, Argentina, presentaron la mesa "Descortesía en comportamientos verbales". Como parte de las ponencias que la integraron, el Dr. Ariel Cordisco expuso los resultados del estudio piloto de la investigación denominada "Actividades de imagen en la expresión sexista de la violencia".

Se planteó la posibilidad de replicar dicha investigación en México, dada la creciente violencia hacia las mujeres en el país. Resulta importante destacar que el $66.8 \%$ de las agresiones en contra de las mujeres ocurridas en la calle son de tipo sexual, tales como: piropos groseros u ofensivos, intimidación, acecho, abuso sexual, violación e intento de violación (ONU Mujeres, 2018, p. 18).

Con base en el Informe de la ONU, 34.3\% de las mujeres han experimentado algún tipo de violencia sexual a lo largo de su vida. El 93.4\% de las mujeres en México que han experimentado violencia física y/o sexual en el ámbito comunitario, no presentó una queja o denuncia ante alguna autoridad; y de esas mujeres, el 49.5\% no denunció por considerar que es un hecho sin importancia. Además, el 76.3\% de las mujeres señaló sentirse más inseguras que los hombres al encontrarse en diversos lugares públicos o privados (Osman, 2019, p. 7).

Resulta pertinente, pues, indagar sobre las expresiones de la violencia simbólica presentes en el discurso social a partir de la normalización del sexismo y de las estructuras heteropatriarcales en la cultura del México contemporáneo.

Cordisco $(2017$, p. 85) desarrolló un instrumento de recolección de datos que se aplicó a 26 informantes de la Ciudad Autónoma de Buenos Aires, con la variable género equiparada. Dicho instrumento requiere detallar o narrar -por parte de quien lo responde-, experiencias personales y reacciones verbales ante situaciones específicas que implican conflicto con hombres y/o mujeres.

La réplica mexicana se llevó a cabo con el mismo instrumento analítico ${ }^{1}$, pero fue necesario adaptar 4 preguntas al lenguaje coloquial y al contexto sociocultural del noreste de México. Estas fueron las siguientes: la pregunta 2 (ciudad en donde se vive) se dejó abierta; la pregunta 5 -título escolar-se adaptó a la nomenclatura de México; en la pregunta 15 se omitió la segunda pregunta -Si se une a la hinchada para cantarle algo, ¿qué le canta?-; y se adaptó la situación 4 supliendo "cocinar asados" por "hacer carne asada".

El cuestionario tiene 17 reactivos. El $1^{\circ}$ es el consentimiento. Si el sujeto no acepta responder el formulario se pasa a la número 17 para cerrar el formulario electrónico. Las respuestas se envían automáticamente. Las preguntas 2 a 6 recogen los datos que caracterizan a los sujetos respondientes (ciudad, sexo, edad, título

${ }^{1}$ El instrumento analítico puede verse en el anexo. 
escolar y ocupación). Las preguntas 7 a 16 son las que exploran las expresiones sexistas. Estas se detallarán más adelante.

Se envió el cuestionario, vía electrónica, a 50 sujetos de diferentes ciudades mediante la plataforma libre Google forms. Solo se recibió respuesta de 35 de ellos. En la Tabla 1 se presentan las frecuencias más altas de las características de los sujetos respondientes.

Tabla 1. Características predominantes de los sujetos respondientes mexicanos.

\begin{tabular}{|l|l|}
\hline & Porcentaje \\
\hline Viven en Saltillo & $88 \%$ \\
\hline Hombres & $51 \%$ \\
\hline Mujeres & $49 \%$ \\
\hline $18-24$ años & $45,7 \%$ \\
\hline Nivel de estudio: Bachillerato & $51,4 \%$ \\
\hline Ocupación: Estudiante & $45,5 \%$ \\
\hline
\end{tabular}

Las características del caso argentino (Cordisco, 2017, p. 85) se presentan en la Tabla 2.

Tabla 2. Características predominantes de los sujetos respondientes argentinos.

\begin{tabular}{|l|l|}
\hline & Porcentaje \\
\hline Viven en Buenos Aires & $100 \%$ \\
\hline Sexo & variable cancelada \\
\hline Mujeres & $49 \%$ \\
\hline $35-49$ años & $35 \%$ \\
\hline Nivel de estudio: Secundario & $42,3 \%$ \\
\hline Ocupación: Técnico Profesional & $50 \%$ \\
\hline
\end{tabular}

El caso argentino manejó la variable sexo de forma equiparada $-50 \%$ mujeres y 50\% hombres- (Cordisco, 2017, p. 85). En el caso de México se dejó abierta, sin embargo resultó estadísticamente equiparada, como se puede ver en la Tabla 1.

\section{Análisis de resultados sobre las experiencias en el ámbito público}

Este apartado tiene dos preguntas, la 7: ¿cuál fue la peor falta de respeto que le ha escuchado a un hombre decirle a una mujer? Y la 8: ¿y cuál fue la peor falta de respeto que le ha escuchado a una mujer decirle a un hombre?

En la Tabla 3 se muestran las frecuencias de respuesta a la pregunta 7.

Tabla 3. Faltas de respeto a la mujer en ámbito público.

\begin{tabular}{|l|l|l|l|l|}
\hline Categoría & $\begin{array}{l}\text { Groserías y } \\
\text { amenazas }\end{array}$ & Puta & $\begin{array}{l}\text { Desacreditar la } \\
\text { capacidad }\end{array}$ & $\begin{array}{l}\text { No } \\
\text { respondió }\end{array}$ \\
\hline Frecuencia & 15 & 12 & 6 & 2 \\
\hline
\end{tabular}

Como se muestra en la Tabla 3, los insultos y amenazas se diversifican en expresiones como pinche ${ }^{2}$ vieja, culera $^{3}$, verdulera, mamona ${ }^{4}$ y te vas a ir a la

\footnotetext{
${ }^{2}$ En México tiene un sentido despectivo, como algo despreciable, ruin o de mala calidad (Academia Mexicana de la Lengua, 2013, p. 466).

${ }^{3}$ Este calificativo refiere a alguien cobarde, traicionero o a alguien malo y sin consideración (Academia Mexicana de la Lengua, 2013, p. 159).

${ }^{4}$ Engreída, presumida (Academia Mexicana de la Lengua, 2013, p. 348).
} 
verga. La idea de 'puta' se expresa en términos como zorra, prostituta, cola suelta y perra.

Los términos para desacreditar la capacidad son estúpida, pendeja ${ }^{5}$, puñetas ${ }^{6}$, buena para nada e inútil.

Como puede verse, la mayoría de los insultos en público están anclados en una consideración de la práctica desmedida del sexo y en una consideración denigrante de lo femenino.

En la Tabla 4 se presentan las frecuencias de respuesta a la pregunta 8 .

Tabla 4. Faltas de respeto al hombre en ámbito público.

\begin{tabular}{|l|l|l|l|l|l|l|}
\hline Categoría & Insultos & $\begin{array}{l}\text { Poco } \\
\text { hombre }\end{array}$ & $\begin{array}{l}\text { Deficiencia } \\
\text { intelectual }\end{array}$ & Maricón/joto & Golpes & $\begin{array}{l}\text { No } \\
\text { respondió }\end{array}$ \\
\hline Frecuencia & 11 & 7 & 7 & 6 & 2 & 2 \\
\hline
\end{tabular}

La Tabla 4 muestra cómo en los insultos al varón hay una tendencia a atacar la hombría con expresiones como poco hombre, maricón, no tiene huevos y en referir prácticas sexuales como puto $^{7}$, joto ${ }^{8}$ y maricón.

Llama la atención que aquí aparezcan dos palabras en femenino: puta y mentirosa. Es significativo que mujeres agredan a los hombres con insultos en femenino o en orden al género, lo que puede explicarse como una reproducción de los sistemas de opresión racial, sexual y de clase occidentales (Bard y Artazo, 2017, p. 209).

Estas respuestas pueden identificarse como "actividades comunicativas que tienden hacia el acoso y la amenaza, presididas por una axiología desvalorizante que opera sobre áreas discursivas relativas a la personalidad, la caracterización sexual, la actividad laboral, y la salud" (Cordisco, 2017, p. 85).

Además, resulta significativo el hecho de que la esfera de 'los lazos familiares' solo aparezca en los insultos al hombre al resaltar la figura materna negativamente-hijo de puta y chingas a tu madre ${ }^{9}$.

\section{Análisis de resultados sobre las experiencias en el ámbito privado}

Este apartado contiene dos preguntas que son idénticas a las del anterior, la 9: ¿cuál fue la peor falta de respeto que le ha escuchado a un hombre decirle a una mujer? Y la 10: ¿y cuál fue la peor falta de respeto que le ha escuchado a una mujer decirle a un hombre? No hay que perder de vista que se considera ahora el ámbito privado.

En la Tabla 5 se muestran las frecuencias de respuestas a la pregunta 9.

Tabla 5. Faltas de respeto a la mujer en ámbito privado.

\footnotetext{
${ }^{5}$ En México, pendejo designa a alguien tonto o falto de entendimiento (Academia Mexicana de la Lengua, 2013, p. 452).

${ }^{6}$ Regionalismo del noreste de México que alude a alguien tonto por causa de la masturbación (Elizondo, 1996, p. 246).

${ }^{7}$ Esta expresión se emplea aquí con la acepción de cobarde o pusilánime e incluso homosexual (Academia Mexicana de la Lengua, 2013, p. 494).

${ }^{8}$ Equivale a homosexual. También lleva el matiz de cobarde o miedoso (Academia Mexicana de la Lengua, 2013, p. 310).

${ }^{9}$ Este insulto es equivalente al insulto argentino -y muy común en Sudamérica- "la concha de tu madre" (Academia Mexicana de la Lengua, 2013, p. 123).
} 


\begin{tabular}{|l|l|l|l|l|l|l|}
\hline Categoría & $\begin{array}{l}\text { Insultos } \\
\text { varios }\end{array}$ & Sexo & $\begin{array}{l}\text { No } \\
\text { hacer } \\
\text { nada }\end{array}$ & $\begin{array}{l}\text { Deficiencia } \\
\text { intelectual }\end{array}$ & $\begin{array}{l}\text { No } \\
\text { respondió }\end{array}$ & Ninguna \\
\hline Frecuencia & 11 & 10 & 6 & 5 & 2 & 1 \\
\hline
\end{tabular}

Llama la atención que, en el caso de las ofensas a las mujeres en lo privado, con respecto al ámbito público, disminuya el aspecto sexual y se incremente el aspecto del no saber hacer las cosas. Una de las respuestas combina ambas esferas: ¿Eres una buena para nada, ni pa' coger! También es significativo señalar que entre los insultos varios se insista en cuatro ocasiones el por ser mujer.

Tabla 6. Faltas de respeto al hombre en ámbito privado.

\begin{tabular}{|l|l|l|l|l|l|l|l|}
\hline Categoría & $\begin{array}{l}\text { Insultos } \\
\text { varios }\end{array}$ & $\begin{array}{l}\text { Poco } \\
\text { hombre }\end{array}$ & $\begin{array}{l}\text { Deficiencia } \\
\text { intelectual }\end{array}$ & Inútil & $\begin{array}{l}\text { No } \\
\text { respondió }\end{array}$ & Mantenido & Maricón \\
\hline Frecuencia & 12 & 5 & 5 & 5 & 4 & 3 & 1 \\
\hline
\end{tabular}

Como se puede apreciar, en el caso del insulto a los hombres se mantienen las tendencias de lo público en lo privado -atacar la hombría y la capacidad intelectual-, a diferencia de lo que ocurre para con las mujeres. Hay que señalar que uno de los insultos varios es mal parido, con el que se ataca al varón y también a la mujer.

\section{Análisis de la Situación 1}

La situación 1 plantea lo siguiente: imagine qué diría en la siguiente situación. Usted viene conduciendo y, de repente, un vehiculo ocupa su carril sin previo aviso. Tiene que maniobrar para no chocar. Luego de unos instantes, puede ver a quien conduce. La pregunta 11 es un conductor mujer y la 12 es un conductor hombre.

En la Tabla 7 se presentan las respuestas más significativas del reactivo 11.

Tabla 7. Frecuencias de respuestas a la pregunta 11.

\begin{tabular}{|l|l|l|l|l|l|}
\hline Categoría & $\begin{array}{l}\text { Incapacidad } \\
\text { intelectual }\end{array}$ & $\begin{array}{l}\text { Sin } \\
\text { ofensa }\end{array}$ & Insultos & $\begin{array}{l}\text { Lazos } \\
\text { familiares }\end{array}$ & $\begin{array}{l}\text { Tenía que ser } \\
\text { hombre }\end{array}$ \\
\hline Frecuencia & 11 & 10 & 6 & 5 & 4 \\
\hline
\end{tabular}

Las respuestas de la pregunta 11 muestran un acumulado de 10 respuestas que explicitan el hecho de ser una mujer a quien se dirigen.

Aquí llama la atención que haya respuestas que no tienen tono ofensivo (cuidado, ten precaución), que podrían explicarse por la situación de violencia generalizada que ha habido en la región a causa de las bandas delincuenciales.

Ahora, en la Tabla 8 se muestran las respuestas del reactivo 12 .

Tabla 8. Frecuencias de respuestas a la pregunta 12.

\begin{tabular}{|l|l|l|l|l|l|}
\hline Categoría & $\begin{array}{l}\text { Incapacidad } \\
\text { intelectual }\end{array}$ & $\begin{array}{l}\text { Sin } \\
\text { ofensa }\end{array}$ & Insultos & $\begin{array}{l}\text { Lazos } \\
\text { familiares }\end{array}$ & $\begin{array}{l}\text { Tenía que ser } \\
\text { hombre }\end{array}$ \\
\hline Frecuencia & 18 & 7 & 3 & 2 & 1 \\
\hline
\end{tabular}

En comparación con los varones, en las mujeres hay mayor presencia de expresiones que refieren la incapacidad intelectual y de expresiones no ofensivas. Además, hay diferencias en el hecho de que se hace hincapié en el género del conductor una sola vez y que a la conductora no le insultan refiriendo a la madre y al conductor en dos ocasiones. 
Esta situación podría explicarse desde la idea existente en el imaginario popular acerca de que el hombre es más hábil para conducir que la mujer. De ahí que a la conductora se le señale por ser mujer y al hombre se le insulte por no corresponder con la supuesta habilidad.

\section{Análisis de la Situación 2}

La situación 2 se enunció así: Imagine qué diría en la siguiente situación. Su pareja se encarga de pagar los impuestos y servicios del hogar. Es viernes por la noche y, mientras está navegando por Facebook, el servicio de cable e internet se corta. Usted llama a la empresa y le informan que el corte se produjo por falta de pago, con tres meses de demora. La pregunta ¿qué le diría a su pareja? se divide en 13 (si la pareja es hombre) y 14 (si la pareja es mujer).

A continuación, se muestra la Tabla 9 con las respuestas a "si la pareja es hombre".

Tabla 9. Frecuencias de respuestas a la pregunta 13.

\begin{tabular}{|l|l|l|l|l|}
\hline Categoría & $\begin{array}{l}\text { Señalar o preguntar } \\
\text { por el pago, sin ofensa }\end{array}$ & $\begin{array}{l}\text { Señalar o preguntar por el } \\
\text { pago, con ofensa }\end{array}$ & Insultos & $\begin{array}{l}\text { No } \\
\text { respondió }\end{array}$ \\
\hline Frecuencia & 24 & 4 & 4 & 3 \\
\hline
\end{tabular}

En las respuestas a la pregunta 13 predomina la actitud de pedir cuentas sobre la omisión, pero no hay ofensas ni agresiones. En el caso de preguntar con ofensas, llama la atención que en dos de las respuestas aparezcan expresiones que apuntan a que el dinero lo gasta el hombre en otras mujeres -cómo no se te olvida estar con las putas o me estas engañando con otra para que te falte el dinero, inútil-.

Se muestra ahora la Tabla 10, con las respuestas a "si la pareja es mujer".

Tabla 10. Frecuencias de respuestas a la pregunta 14.

\begin{tabular}{|l|l|l|l|l|l|l|l|}
\hline Categoría & $\begin{array}{l}\text { Señalar o } \\
\text { preguntar } \\
\text { por el } \\
\text { pago, sin } \\
\text { ofensa }\end{array}$ & $\begin{array}{l}\text { Tono } \\
\text { conciliador }\end{array}$ & Insultos & Reclamo & $\begin{array}{l}\text { No } \\
\text { respondió }\end{array}$ & Reproche & Eufemismo \\
\hline Frecuencia & 19 & 6 & 3 & 3 & 2 & 1 & 1 \\
\hline
\end{tabular}

En las respuestas a la pregunta 14, llama la atención el hecho de que 19 respuestas piden cuentas sobre la omisión sin incluir ofensas y 6 más aparecen en un tono conciliador: avisame antes; no importa mañana lo pagamos o espere ya voy a pagar.

De los grupos de respuestas llama la atención, en primer lugar, que haya una serie de respuestas en tono conciliador hacia la pareja mujer, cosa que no existe en las respuestas hacia la pareja hombre. En el caso de la pareja mujer se le insulta y reprocha con no haces nada o pendeja, lo que ya aparecía en los insultos del ámbito privado. también llama la atención aquí la aparición de un eufemismo: ay amor, un tanto idiota, que busca atenuar la agresión -idiota- con la expresión cariñosa -ay amor-.

Resulta significativo que en esta Situación 2 haya una mayor presencia de violencia simbólica de la mujer hacia el hombre.

\section{Análisis de la Situación 3}


La pregunta 15 se da con la siguiente situación: Imagine que es su costumbre ir a ver el juego de su equipo favorito en el estadio. Este domingo le toca presenciar el juego dirigido por un árbitro mujer. Hacia el final del juego, la árbitra marca una falta que compromete el resultado en contra de su equipo. ¿Qué le diría a la árbitra?

Las respuestas están se agrupan de la siguiente forma en la Tabla 11:

Tabla 11. Frecuencias de respuestas a la pregunta 15.

\begin{tabular}{|l|l|l|l|l|l|l|l|l|}
\hline Categoría & $\begin{array}{l}\text { Fíjate/pon } \\
\text { atención }\end{array}$ & Vendida & $\begin{array}{l}\text { Está } \\
\text { idiota }\end{array}$ & Nada & $\begin{array}{l}\text { No } \\
\text { respondió }\end{array}$ & Ciega & $\begin{array}{l}\text { Te crio } \\
\text { un } \\
\text { hombre }\end{array}$ & $\begin{array}{l}\text { Que } \\
\text { repitan } \\
\text { la } \\
\text { jugada }\end{array}$ \\
\hline Frecuencia & 10 & 8 & 6 & 5 & 2 & 1 & 1 & 1 \\
\hline
\end{tabular}

La Tabla 11 muestra que la mayoría de las respuestas son iguales a las que se le suelen gritar a los árbitros, con todo e insultos, en un evento deportivo en los que esta violencia verbal es muy común. En los cuestionarios recibidos, solo una de las respuestas detalla que lo más común sería, ella no sabe del deporte, dejando al implícito que no sabe de deportes por el hecho de ser mujer, si se apela al imaginario popular. Solamente dos respuestas tienen un carácter explícitamente sexista, una contra la mujer: vendida, se ha de acostar con todo el equipo; y la otra contra el varón: te crio un hombre, que resulta paradójica al insultar a la mujer al hacerla semejante al varón.

\section{Análisis de la Situación 4}

La última pregunta (16) se propone a partir de la siguiente situación: Imagine que es su costumbre ofrecerse a hacer carne asada los sábados por la noche para sus familiares. Este sábado las mujeres de la familia insisten en encargarse ellas de la carne asada y usted acepta. Sin embargo, la cena se retrasa más de la cuenta a y la carne asada resulta no estar bien cocinada. ¿Qué les diría?

La Tabla 12 presenta las frecuencias de respuesta.

Tabla 12. Frecuencias de respuestas a la pregunta 16.

\begin{tabular}{|l|l|l|l|l|l|l|l|l|l|l|}
\hline Categoría & $\begin{array}{l}\text { No } \\
\text { pasa } \\
\text { nada }\end{array}$ & $\begin{array}{l}\text { Porque } \\
\text { son } \\
\text { mujeres }\end{array}$ & $\begin{array}{l}\text { Última } \\
\text { vez }\end{array}$ & $\begin{array}{l}\text { No } \\
\text { saben } \\
\text { cocinar }\end{array}$ & Reclamos & Bromas & $\begin{array}{l}\text { Eso } \\
\text { no es } \\
\text { gratis }\end{array}$ & $\begin{array}{l}\text { No } \\
\text { comer }\end{array}$ & $\begin{array}{l}\text { Está } \\
\text { cruda }\end{array}$ & $\begin{array}{l}\text { No } \\
\text { respondió }\end{array}$ \\
\hline Frecuencia & 11 & 7 & 4 & 5 & 3 & 1 & 1 & 1 & 1 & 1 \\
\hline
\end{tabular}

Del grupo de respuestas de la pregunta 16, solo 7 explicitan la cuestión de género para reclamar la situación: las mujeres no sirven para asar carne. Ahora bien, las 5 respuestas que señalan 'no saben cocinar', si se apela al imaginario popular, implica una situación que sería propia de su género y no saberlo hacer produce una imagen negativa de la mujer.

\section{Discusión}

La réplica mexicana del instrumento arroja, de manera general, resultados muy semejantes a los obtenidos en sujetos argentinos. Esta situación podría explicarse por una hegemonía cultural machista que se comparte en el subcontinente latinoamericano. Por ello se está de acuerdo con Cordisco (2017) al señalar que: 
[...] en términos de actividades de imagen, se considera la conformación de un rol sexista estructurado a partir de la elaboración discursiva de un posicionamiento actitudinal, sexual, productivo, interpersonal y perlocutivo que estaría presupuesto por una matriz ideológica machista o heteropatriarcal y que contribuiría en su reproducción. Estas actividades responden a necesidades de imagen refractarias o de afiliación exacerbada de una agresividad crónica normativa y estructurante [...] (Cordisco, 2017, p. 85).

Las actividades de descortesía prevalecientes en la construcción de estas imágenes son del tipo de descortesía de fustigación (Kaul de Marlangeon, 2008, p. 262) que se muestra en los insultos y agresiones intencionadamente dirigidos al oyente. Pero también está presente la refractariedad, pues hay una oposición al grupo hombres o mujeres y la afiliación exacerbada que actúa inversamente proporcional a la refractariedad como adeptos al propio grupo (Kaul de Marlangeon, 2004, p. 166).

El rasgo más significativo de la imagen femenina deteriorada, en público, es el de puta y en privado, el de no sabe hacer nada. Refractariamente, la imagen de varón se delinearía como alguien moralmente digno -público- y que lo sabe y lo puede todo -privado-.

En el caso del varón, los rasgos más significativos de la imagen deteriorada, en lo público y en lo privado, es el de poco hombre, maricón y estúpido. Por refractariedad, la mujer aparece como superior intelectual, moral y físicamente.

También se agregan otros rasgos a estas imágenes que, si bien ambas pueden estar marcadas por el mismo calificativo (v. gr. pendejo/a), el contexto matiza adecuadamente el simbolismo del insulto. En las situaciones descritas existe un elemento que se podría denominar "reprochable" y que detona el conflicto entre los sujetos. Pero la estructura social reproducida que asigna roles sexistas hace que resuene con mayor fuerza llamarle pendejo a un hombre que no sabe manejar que a una mujer o inútil a una mujer que no cocina.

Ahora bien, Cordisco (comunicación personal, septiembre 12, 2019) construye 8 campos discursivos a partir de las respuestas obtenidas (Figura 1).

Figura 1. Campos discursivos. Elaborada por Cordisco (2019) y editada por los autores.

\begin{tabular}{|l|}
\hline \multicolumn{1}{|c|}{ Campos discursivos } \\
\hline Personalidad \\
\hline Sexualidad \\
\hline Habilidad \\
\hline Acoso, Amenazas \\
\hline Imperativos \\
\hline Lazo familiar \\
\hline Salud \\
\hline Silencio \\
\hline
\end{tabular}

Con base en esos mismos campos discursivos, se pueden identificar las posiciones exclusivas sexistas de mujeres a hombres y de hombres a mujeres y los recursos comunicativos descorteses que se derivan de ellos y en función de qué campo discursivo están.

La ideología heteropatriarcal se muestra claramente como el contexto desde donde se asignan roles, casi exclusivos, a hombres y mujeres a partir de los cuales se consolidan los criterios éticos (bien/mal), los criterios epistemológicos (saber/no 
saber o verdad/error) y hasta los criterios de salud (sano/enfermo) que se combinan entre sí.

De esta forma, si el varón es poco hombre, maricón y estúpido, no cumple con los parámetros que la ideología le impone y queda completamente desacreditado ante los demás y ante sí mismo. A partir de los criterios antes mencionados, está enfermo (maricón), no sabe y está en el error (estúpido) lo que lo vuelve o hace que se le perciba como malo (poco hombre). De la misma manera, si la mujer es puta y no sabe hacer nada, tampoco tiene lugar en un mundo construido desde este tipo de ideología y de criterios.

\section{Conclusiones}

1) Las posiciones enunciativas sexistas exclusivas activan recursos comunicativos descorteses en función del ámbito en que se mueven las personas (público o privado).

2) Estos recursos, de mujeres a hombres, en el ámbito público, están en función de la personalidad por carencia sexual y distorsión de atributos físicos. y de habilidad.

3) En el ámbito privado, mujer a hombre, predominan también los recursos comunicativos descorteses en el campo de la personalidad por discapacidad sexual y se añade el de lo intelectual.

4) Los recursos comunicativos descorteses de hombres a mujeres en el ámbito público, están en función de la estigmatización del campo de la sexualidad, no por carencia, sino por exceso; seguida del de la personalidad por discapacidad intelectual.

5) En el ámbito privado, de hombre a mujer, estos recursos mantienen la función de estigmatización del campo de la sexualidad por exceso, seguido por el de carencia de habilidad.

6) Resulta significativo que no aparezca, en los insultos a la mujer, el campo de lazos familiares (insultos a la madre), que por el contrario sí aparece en los insultos al hombre. Esta situación, podría explicarse por la marcada presencia de la figura de la madre en la cultura mexicana y que es casi un tabú entre los varones, lo que vuelve más agresivo al insulto sobre la madre para los hombres que para las mujeres (Paz, 1993, p. 85), aunque no por ello deja de ser un insulto también para la mujer.

7) Es relevante señalar que las expresiones de consideración para con la pareja solo aparecen del hombre para con la mujer, así como el eufemismo (campo discursivo de silencio), que no aparece de la mujer al hombre.

8) También es importante destacar que las amenazas y el acoso aparecen explícitas solamente en las actitudes del hombre para con la mujer. Es necesario insistir en ello porque son un verdadero problema social en México, como lo han denunciado muchos colectivos y agrupaciones femeninas.

9) Finalmente, se estima la aplicación del instrumento a más sujetos, de otras regiones de México, para contrastar los resultados y revisar la posibilidad de generar otros campos discursivos con sus respectivas categorías y subcategorías. 
También queda para posteriores trabajos realizar un acercamiento a los procesos de normalización de la violencia simbólica y de la descortesía en el plano sexista, que derivan en las prácticas de no denuncia de las conductas agresivas.

$\mathrm{Y}$ se proyecta hacer una adaptación de este instrumento analítico para explorar las actividades de imagen y la violencia simbólica en miembros de la comunidad LGTB.

\section{Referencias}

1. Academia Mexicana de la Lengua (2013). Diccionario de mexicanismos. México: Siglo XXI.

2. Bard, G. y Artazo, G. (2017). Pensamiento feminista Latinoamericano: Reflexiones sobre la colonialidad del saber/poder y la sexualidad. Cultura y representaciones sociales, 22, pp. 193-219.

3. Cordisco, A. (2017). Actividades de imagen en la expresión sexista de la violencia simbólica y la descortesía verbal. En Asociación Latinoamericana de Estudios del Discurso (Ed.). Discurso, construcción y transformación social. XII Congreso Internacional ALED (p. 85). Santiago: Pontificia Universidad Católica de Chile.

4. Cordisco, A. (2019). Comunicación personal. Septiembre 12.

5. Elizondo, R. (1996) Lexicón del noreste de México. México: Fondo de Cultura Económica.

6. ONU Mujeres (2018). Informe anual 2018. México. México: Organización de Naciones Unidas.

7. Osman, Y. (Coord.) (2019). Informe de resultados. Programa ciudades y espacios públicos seguros para mujeres y niñas en México. México: Entidad de las Naciones Unidas para la Igualdad de Género y el Empoderamiento de las Mujeres.

8. Kaul de Marlangeon, S. (2004). Descortesía intragrupal-crónica en la interacción coloquial de clase media baja del español rioplatense. En Murillo Medrano, J. (Ed.), Actas del II Coloquio Internacional del Programa EDICE. "Actos de habla y cortesía en distintas variedades del español: perspectivas teóricas y metodológicas" (pp. 155-179). San José de Costa Rica: Universidad de Costa Rica-Programa EDICE.

9. Kaul de Marlangeon, S. (2008). Tipología del comportamiento verbal descortés en español. En Briz, A., Albelda, M y Hernández, N. (Eds.). Cortesía y conversación: de lo escrito a lo oral. Tercer Coloquio Internacional del Programa EDICE (Vol. 3, pp. 254-266). ValenciaEstocolmo: Universidad de Valencia-Programa EDICE.

10. Paz, O. (1993). El laberinto de la soledad -Postdata- Vuelta a El Laberinto de la soledad. México: Fondo de Cultura Económica.

\section{Anexo}

Instrumento analítico aplicado en la réplica.

Este estudio se enmarca en las actividades de investigación aprobadas por la Facultad de Ciencia, Educación y Humanidades de la Universidad Autónoma de Coahuila. (Proyecto del CA "Discursos, semióticas y lenguajes. Estudios de la cultura en la región". No hay respuestas correctas o incorrectas: simplemente responda según su experiencia personal y laboral.

Los datos que se recaben aquí tienen un objetivo estrictamente académico. No hay consecuencia, riesgo, beneficio directo o compensación por responder este cuestionario. El grupo de investigación responsable de este proyecto garantiza preservar el anonimato y la confidencialidad de los datos. Ninguna información personal será compartida con terceros. *Obligatorio 
Para continuar, responda al siguiente consentimiento. El asterisco $(*)$ indica que es obligatorio responder a la pregunta planteada.

1. ¿Desea responder este cuestionario? * Marca solo un óvalo.

\section{Sí}

No. Pasa a la pregunta 17

Datos demográficos

2. Ciudad

3. Sexo

Marca solo un óvalo.

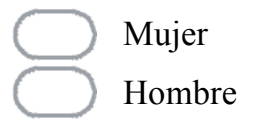

4. Edad

Marca solo un óvalo.

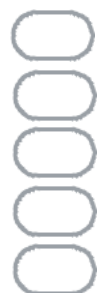

$18-24$

25-34

$35-49$

50-59

60 y más

5. Título escolar Marca solo un óvalo.

Primaria

Secundaria

Bachillerato, Preparatoria o equivalente

Universitario

Posgrado

6. Ocupación

Marca solo un óvalo.

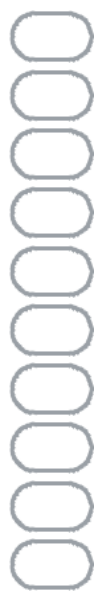

Estudiante

Ama de casa

Jubilado

Docente

Empleado de comercio

Ejecutivo

Oficio (plomero, carpintero, taxista, etc.).

Técnico profesional

Desocupado

Otro

\section{Experiencias en el ámbito público}

Recuerde alguna situación vivida en la calle, el trabajo, la escuela, el colectivo o cualquier otro lugar o medio público. Transcriba las palabras tal cual las escuchó.

7. ¿Cuál fue la peor falta de respeto que le ha escuchado a un hombre decirle a una mujer? 
8. ¿Y cuál fue la peor falta de respeto que le ha escuchado a una mujer decirle a un hombre?

\section{Experiencias en el ámbito privado}

Recuerde alguna situación viva en su hogar, en una reunión de amigos, por teléfono o cualquier otro lugar o medio privado, Transcriba las palabras tal cual las escuchó.

9. ¿Cuál fue la peor falta de respeto que le ha escuchado a un hombre decirle a una mujer? 10. ¿Y cuál fue la peor falta de respeto que le ha escuchado a una mujer decirle a un hombre?

Situación 1 (de 4)

Imagine qué diría en la siguiente situación. Usted viene conduciendo y, de repente, un vehículo ocupa su carril sin previo aviso. Tiene que maniobrar para no chocar. Luego de unos instantes, puede ver a quien conduce.

\section{Conductor mujer \\ 12. Conductor hombre}

\section{Situación 2 (de 4)}

Imagine qué diría en la siguiente situación. Su pareja se encarga de pagar los impuestos y servicios del hogar. Es viernes por la noche y, mientras está navegado por el Facebook, el servicio de cable e internet se corta. Usted llama a la empresa y le informan que el corte se produjo por falta de pago, con tres meses de demora.

13. Su pareja es un hombre. ¿Qué le dice?

14. Su pareja es mujer. ¿Qué le dice?

\section{Situación 3 (de 4)}

Imagine que es su costumbre ir a ver el juego de su equipo favorito en el estadio. Este domingo le toca presenciar el juego dirigido por un árbitro mujer. Hacia el final del juego, la árbitra marca una falta que compromete el resultado en contra de su equipo.

15. ¿Qué le diría a la árbitra?

Situación 4 (de 4)

Imagine que es su costumbre ofrecerse a hacer carne asada los sábados por la noche para sus familiares. Este sábado las mujeres de la familia insisten en encargarse ellas de la carne asada y usted acepta. Sin embargo, la cena se retrasa más de la cuenta y la carne asada resulta no estar bien cocinada.

16. ¿Qué les diría?

17. Selecciona todas las opciones que correspondan*

Marca solo un óvalo

Terminar cuestionario

Gracias por su interés en este estudio. Su participación es muy valorada. 